\title{
A CLINICAL, BACTERIOLOGICAL AND LABORATORIES PROFILE OF NEONATAL SEPTICAEMIA IN A TERTIARY CARE CENTRE OF EASTERN NEPAL
}

\author{
Pramendra Prasad Gupta1, Sanjay Gupta², Rupak Bhandari3 , Shital Gupta4, Lokraj Shah ${ }^{5}$ \\ ${ }_{1}^{1}$ Associate Professor, Department of General Practice and Emergency Medicine, B. P. Koirala Institute of Health Sciences. \\ ${ }^{2}$ Private Practitioner. \\ ${ }^{3}$ Assistant Professor, Department of General Practice and Emergency Medicine, B. P. Koirala Institute of Health Sciences. \\ ${ }^{4}$ Senior Resident, Department of Basic and Clinical Physiology, B. P. Koirala Institute of Health Sciences. \\ ${ }_{5}^{5}$ Assistant Professor, Department of Paediatrics and Adolescent Medicine, B. P. Koirala Institute of Health Sciences.
}

\section{ABSTRACT}

\section{BACKGROUND}

The most common neonatal morbidity and mortality in underdeveloped countries is neonatal sepsis. The vague clinical sign and symptoms need high degree of suspicion for the early diagnosis and treatment, while the continuously changing patterns of causative microbial flora and their sensitivity pattern cause problem in effective management of these cases.

\section{MATERIALS AND METHODS}

This retrospective descriptive study was conducted by studying the case reports of 325 newborns, which were (both inborn and outborn) admitted to BPKIHS Paediatric Ward, Nursery, NICU via Emergency over a period of one year from January 2012 to December 2012 with features suggestive of sepsis.

\section{RESULTS}

The total number of patients enrolled in this study was 325. Among them, 213 (65.5\%) were male and 112 (34.5\%) were female child. Male-to-female ratio was almost 2: 1 . Early onset sepsis was found in 56.6\% newborns, while $43.4 \%$ had late onset sepsis. Most of the newborns were presented with the complaints of fever (46.8\%) followed by refusal of feed (39.7\%) and respiratory distress. Blood culture from $13.2 \%$ newborns showed growth of pathologic organism.

\section{CONCLUSION}

Male sex has more tendency to develop neonatal sepsis than female. The risk of developing sepsis in male child is almost twice that of female child, which was statistically significant. The various risk factors are leaking, low birth weight, size corresponding to gestational age and prematurity. Fever, not sucking well, resp. distress, jaundice, lethargy, vomiting and seizure were the main chief complaints. Blood culture positivity rate was $13.2 \%$ with predominance of gram-positive organisms.

\section{KEYWORDS}

Bacteraemia, Causative Microbial Flora, Neonatal Sepsis.

HOW TO CITE THIS ARTICLE: Gupta PP, Gupta S, Bhandari R, et al. A clinical, bacteriological and laboratories profile of neonatal septicaemia in a tertiary care centre of eastern Nepal. J. Evolution Med. Dent. Sci. 2018;7(01):33-36, DOI: 10.14260/jemds/2018/9

\section{BACKGROUND}

Neonatal sepsis is defined as a clinical syndrome of bacteraemia with systemic signs and symptoms of infection in the first 4 weeks of life. When pathogenic bacteria gain access into the blood stream, they may cause overwhelming infection without much localisation (septicaemia) or may get predominantly localised to the lung (pneumonia) or the meninges (meningitis).

Neonatal sepsis is the single most important cause of neonatal deaths in the community, accounting for over half of them. If diagnosed early and treated aggressively with antibiotics and good supportive care, it is possible to save most cases of neonatal sepsis. The incidence of neonatal sepsis varies from 1 - 8/ 1000 live births in developed countries to 10 - 50/ 1000 live births in developing countries

'Financial or Other Competing Interest': None.

Submission 12-11-2017, Peer Review 13-12-2017,

Acceptance 18-12-2017, Published 01-01-2018.

Corresponding Author:

Dr. Pramendra Prasad Gupta,

Department of General Practice and Emergency Medicine,

B. P. Koirala Institute of Health Sciences,

Dharan, Nepal.

E-mail: dr.pramen@gmail.com

DOI: $10.14260 /$ jemds $/ 2018 / 9$ and incidence in premature baby is $1 / 250$ premature live births. Meningitis occurs in one-third of sepsis cases. Most cases of neonatal sepsis in the community are caused by Group B streptococcus; E. coli and Listeria in developed countries while Staphylococcus aureus, E. coli and Klebsiella causes majority of infection in developing countries. In hospitals, Klebsiella pneumoniae is also a common organism.

This study was done to study the various clinical presentations, laboratory profiles of neonatal sepsis as well as the risk factors causing neonatal sepsis. This study also assessed the organisms responsible for neonatal sepsis with its outcome.

\section{MATERIALS AND METHODS}

This was a retrospective descriptive study conducted by studying the case reports of 325 newborns, which was (both inborn and outborn) admitted to BPKIHS Paediatric Ward, Nursery, NICU via Emergency over a period of one year from January 2012 to December 2012 with features suggestive of sepsis.

Information was recorded on a prepared proforma from the case reports. The information relating to maternal factors included period of gestation, h/o leaking, duration of leaking, place and type of delivery. The information relating to the newborn included age, sex and weight of the baby, presenting 
complaints, complete physical examination, blood culture and sensitivity test and outcome of the disease.

From the collected data the common presenting complaints, age at onset, common risk factors (both maternal and neonatal), physical findings, culture and sensitivity patterns, antibiotics use and the outcome were studied. The cases were divided into early onset sepsis (EOS) and late onset sepsis (LOS) on the basis of time of clinical presentation. Those presented within first 72 hours of life were diagnosed as EOS and after 72 hours of life as LOS.

\section{Sepsis was suspected in the following conditions At Birth}

All newborns (i) born to mothers with maternal fever or prolonged rupture of membrane ( $>18$ hours) or foul smelling or meconium stained liquor and/ or (ii) having severe prematurity or birth asphyxia necessitating active resuscitation.

\section{After Birth}

All neonates with lethargy, refusal to feeds, abdominal distension, respiratory distress, temperature instability (hypothermia/ fever), pathological jaundice, seizures, vomiting and autonomic dysfunction.

The data entry was done on Microsoft Excel 2007 and correlation between different variables was found out using SPSS 10.1. The demographic characters of Neonates and Maternal is shown in tables. The comparison and association is done with Chi-square test.

\section{RESULTS}

The total number of patients enrolled in this study was 325 . Among them, 213 (65.5\%) were male and 112 (34.5\%) were female child. Male-to-female ratio was almost 2: 1 . This study also shows that neonatal sepsis is more common in children of age less than 7 days (69.5\%) than in children of more than 7 days (30.5\%). The mean age of children was 6.4 days.

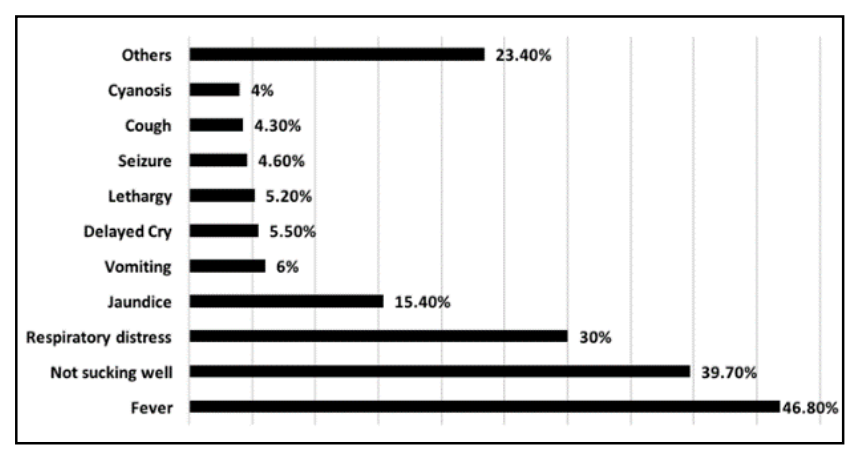

Figure 1. Presenting Complaints of Neonatal Sepsis

\begin{tabular}{|c|c|c|c|}
\hline \multirow{2}{*}{ Variables } & Distribution & $\begin{array}{c}\text { Numbe } \\
\text { r }\end{array}$ & $\begin{array}{c}\text { Percentag } \\
\mathbf{e}\end{array}$ \\
\hline \multirow{2}{*}{ Sex } & Male & 213 & 65.54 \\
\cline { 2 - 4 } Age & Female & 112 & 34.46 \\
\hline \multirow{3}{*}{ Place of Delivery } & $\begin{array}{c}\text { Early onset }(\leq 72 \\
\text { hours) }\end{array}$ & 184 & 56.62 \\
\cline { 2 - 4 } & $\begin{array}{c}\text { Late onset (> 72 } \\
\text { hours) }\end{array}$ & 141 & 43.38 \\
\cline { 2 - 4 } & Inborn & 140 & 43.08 \\
\hline Period of Gestation & Outborn & 185 & 56.92 \\
\cline { 2 - 4 } & $<34$ weeks & 18 & 5.54 \\
\hline
\end{tabular}

\begin{tabular}{|c|c|c|c|}
\hline & $>37$ weeks & 269 & 82.77 \\
\hline \multirow{2}{*}{$\begin{array}{l}\text { Leaking per } \\
\text { vaginum }\end{array}$} & Yes & 116 & 35.69 \\
\hline & No & 209 & 64.31 \\
\hline \multirow{3}{*}{ Mode of delivery } & Normal Vaginal & 255 & 78.46 \\
\hline & Assisted & 6 & 1.85 \\
\hline & LSCS & 64 & 19.69 \\
\hline \multirow{3}{*}{ Neonatal size } & SGA & 55 & 16.92 \\
\hline & AGA & 263 & 80.92 \\
\hline & LGA & 7 & 2.15 \\
\hline \multirow{4}{*}{$\begin{array}{l}\text { Birth } \\
\text { weight }\end{array}$} & ELBW & 1 & 0.31 \\
\hline & VLBW & 19 & 5.85 \\
\hline & LBW & 113 & 34.77 \\
\hline & NBW & 192 & 59.08 \\
\hline \multirow{3}{*}{ Heart rate } & $<120$ & 8 & 2.46 \\
\hline & 120 to 160 & 288 & 88.62 \\
\hline & $>160$ & 29 & 8.92 \\
\hline \multirow{3}{*}{ Respiratory rate } & $<60$ & 223 & 68.62 \\
\hline & 60 to 80 & 96 & 29.54 \\
\hline & $>80$ & 6 & 1.85 \\
\hline \multirow{3}{*}{ PCV } & $<40 \%$ & 104 & 32.00 \\
\hline & $40-65 \%$ & 219 & 67.38 \\
\hline & $>65 \%$ & 2 & 0.62 \\
\hline \multirow{3}{*}{ TLC } & $<5000$ & 5 & 1.54 \\
\hline & 5000 to 15000 & 139 & 42.77 \\
\hline & $>15000$ & 151 & 46.46 \\
\hline \multirow{2}{*}{ Bilirubin } & $<15 \mathrm{mg} / \mathrm{dL}$ & 215 & 66.15 \\
\hline & $\geq 15 \mathrm{mg} / \mathrm{dL}$ & 105 & 32.31 \\
\hline \multirow{2}{*}{ Blood glucose } & $<60 \mathrm{mg} / \mathrm{dL}$ & 70 & 21.54 \\
\hline & $\geq 60 \mathrm{mg} / \mathrm{dL}$ & 255 & 78.46 \\
\hline \multirow{2}{*}{ Blood culture } & Positive & 43 & 13.23 \\
\hline & Sterile & 282 & 86.77 \\
\hline \multirow{3}{*}{ Outcome } & Improved & 263 & 80.92 \\
\hline & LAMA & 38 & 11.69 \\
\hline & Death & 24 & 7.38 \\
\hline
\end{tabular}

\begin{tabular}{|c|c|c|c|c|}
\hline \multirow{2}{*}{\multicolumn{2}{|c|}{ Variables }} & \multicolumn{2}{|c|}{ Blood Culture } & \multirow{2}{*}{\begin{tabular}{|c} 
P-value \\
(Chi- \\
Square \\
Test) \\
\end{tabular}} \\
\hline & & \multirow{2}{*}{$\begin{array}{c}\text { Sterile } \\
184(88.0 \%)\end{array}$} & \multirow{2}{*}{$\begin{array}{c}\text { Positive } \\
25(12 \%) \\
\end{array}$} & \\
\hline \multirow{2}{*}{ Leaking } & No & & & \multirow{2}{*}{0.36} \\
\hline & Yes & 98 (84.5\%) & $18(15.5 \%)$ & \\
\hline \multirow{5}{*}{$\begin{array}{l}\text { Duration of } \\
\text { leaking } \\
\text { (hrs.) }\end{array}$} & $<6$ & $12(12.24 \%)$ & $1(5.55 \%)$ & \multirow{5}{*}{0.049} \\
\hline & $6-12$ & $22(22.44 \%)$ & $2(11.11 \%)$ & \\
\hline & $12-18$ & $11(11.2 \%)$ & $1(5.55 \%)$ & \\
\hline & $18-24$ & $22(22.44 \%)$ & $4(22.22 \%)$ & \\
\hline & $>24$ & $31(31.63 \%)$ & $10(55.55 \%)$ & \\
\hline $\begin{array}{l}\text { Period of } \\
\text { gestation }\end{array}$ & $\begin{array}{c}<37 \\
\text { Weeks }\end{array}$ & $32(82.05 \%)$ & 7 (17.94\%) & 0.859 \\
\hline $\begin{array}{l}\text { Period of } \\
\text { gestation }\end{array}$ & $\begin{array}{c}\geq 37 \\
\text { Weeks }\end{array}$ & $250(87.41 \%)$ & $36(12.58 \%)$ & 0.859 \\
\hline Size of baby & SGA & $42(76.36 \%)$ & $13(23.63 \%)$ & 0.025 \\
\hline \multirow{2}{*}{ Size of baby } & AGA & $234(88.97 \%)$ & $29(11.02 \%)$ & \multirow{2}{*}{0.025} \\
\hline & LGA & $6(85.71 \%)$ & $1(14.28 \%)$ & \\
\hline $\begin{array}{l}\text { Pre-lacteal } \\
\text { feed }\end{array}$ & No & $263(86.79 \%)$ & $40(13.20 \%)$ & 1.00 \\
\hline $\begin{array}{c}\text { Pre-lacteal } \\
\text { feed }\end{array}$ & Yes & $19(86.36 \%)$ & $3(13.63 \%)$ & 1.00 \\
\hline Outcome & LAMA & $35(10.77 \%)$ & $3(0.92 \%)$ & 0.153 \\
\hline \multirow{2}{*}{ Outcome } & Improved & $224(68.92 \%)$ & $39(12.00 \%)$ & \multirow{2}{*}{0.153} \\
\hline & Death & $23(7.08 \%)$ & $1(0.31 \%)$ & \\
\hline & & Variables & & \\
\hline
\end{tabular}




\begin{tabular}{|c|c|c|c|c|c|c|c|}
\hline Organism & $\begin{array}{c}\text { Staph. aureus } \\
(n=24)\end{array}$ & $\begin{array}{c}\text { Enterobacter } \\
(n=6)\end{array}$ & $\begin{array}{c}\text { Enterococcus } \\
(n=6)\end{array}$ & $\begin{array}{l}\text { Acinetobacter } \\
\qquad(n=4)\end{array}$ & $\begin{array}{c}\text { Pseudomonas } \\
(n=3)\end{array}$ & E. $\operatorname{coli}(n=1)$ & $\begin{array}{c}\text { Morganella } \\
(n=1)\end{array}$ \\
\hline Amikacin & $19(79.16 \%)$ & $3(50 \%)$ & 0 & $3(75 \%)$ & $3(100 \%)$ & $1(100 \%)$ & $1(100 \%)$ \\
\hline Amoxyclav & $4(16.67 \%)$ & 0 & 0 & 0 & 0 & 0 & 0 \\
\hline Azithromycin & $1(4.16 \%)$ & 0 & 0 & 0 & 0 & 0 & 0 \\
\hline Cephalexin & $5(20.83 \%)$ & $2(33.33 \%)$ & $1(16.67 \%)$ & $2(50.00 \%)$ & 0 & 0 & 0 \\
\hline Cefotaxime & $2(8.33 \%)$ & 0 & 0 & 0 & 0 & 0 & $1(100 \%)$ \\
\hline Ceftriaxone & $2(8.33 \%)$ & $1(16.67 \%)$ & 0 & $1(25.00 \%)$ & $2(66.67 \%)$ & 0 & $1(100 \%)$ \\
\hline Ceftazidime & $3(12.50 \%)$ & $1(16.67 \%)$ & 0 & $1(25.00 \%)$ & $1(33.33 \%)$ & $1(100 \%)$ & $1(100 \%)$ \\
\hline Chloramphenicol & 0 & 0 & 0 & 0 & 0 & $1(100 \%)$ & 0 \\
\hline \begin{tabular}{|c|} 
Ciprofloxacin \\
\end{tabular} & $14(58.33 \%)$ & $2(33.33 \%)$ & $3(50.00 \%)$ & $2(50.00 \%)$ & $3(100.00 \%)$ & $1(100 \%)$ & 0 \\
\hline Cotrimoxazole & $1(4.16 \%)$ & $1(16.67 \%)$ & 0 & $1(25.00 \%)$ & 0 & 0 & 0 \\
\hline Gentamycin & $14(58.33 \%)$ & 0 & 0 & 0 & $3(100.00 \%)$ & 0 & 0 \\
\hline Penicillin & $2(8.33 \%)$ & 0 & 0 & 0 & $2(66.67 \%)$ & 0 & 0 \\
\hline Nitrofurantoin & 0 & 0 & $1(16.67 \%)$ & 0 & 0 & 0 & 0 \\
\hline Ofloxacin & $7(29.16 \%)$ & $3(50.00 \%)$ & $3(50.00 \%)$ & $3(75.00 \%)$ & 0 & $1(100 \%)$ & 0 \\
\hline Vancomycin & $13(54.16 \%)$ & $2(33.33 \%)$ & $5(83.33 \%)$ & $2(50.00 \%)$ & 0 & 0 & 0 \\
\hline \multicolumn{8}{|c|}{ Table 3. Drug Sensitivity Pattern of different Isolated Bacteria } \\
\hline
\end{tabular}

\section{DISCUSSION}

Neonatal septicaemia encompasses systemic infections of newborn including septicaemia, meningitis, pneumonia, UTI and osteomyelitis of newborn. The incidence of neonatal sepsis varies 1 - 10 per 1000 live births.

Our study showed that the male: female ratio of 1.9: 1 , which means male had more chances of going into sepsis in comparable to females. This was comparable to the study done by Shaw CK et al, who showed male: female ratio of 1.86: 1.1 Among the newborns presented with features of sepsis, $53 \%$ were outborn.

In this study among early onset sepsis and late onset sepsis, early onset sepsis was more common. Early onset sepsis was found in $56.6 \%$ newborns, while $43.4 \%$ had late onset sepsis which is in contrast to the study done by Shrestha $\mathrm{P}$ et al where there was preponderance of late onset sepsis (66.9\%). ${ }^{2}$ Most of the newborns delivered preterm are prone to sepsis. In this study also, $17.2 \%$ of the newborns were delivered preterm, which contrasts the Gerd Faxelius et al, ${ }^{3}$ which showed $53 \%$ of the newborn delivered preterm. The value also contrasts the study done by Budhathoki $\mathrm{S}$ in BPKIHS, Dharan, $\mathrm{Nepal}^{4}$ where $48 \%$ of the neonates were delivered preterm.

History of leaking was present in mothers of $36 \%$ neonates. The value is nearly comparable with the $46 \%$ obtained by Budhathoki S in BPKIHS, Dharan, Nepal.4 Among them $68.1 \%$, i.e. $24.30 \%$ of total had leaking for more than 12 hours. The value is about half the value of $48 \%$, observed by Gerd Faxelius et al. ${ }^{3}$ The mode of delivery is normal vaginal delivery in $78.5 \%$ neonates, while $21.5 \%$ were delivered through LSCS and/or instrumental delivery. This is comparable with Budhathoki $\mathrm{S}^{4}$ (23\% LSCS). Similar results were found by Gerd Faxelius et al, ${ }^{3}$ which showed 26\% LSCS delivery. Slightly higher value was obtained by Ayman Koutbuoy, 5 who observed $38.67 \%$ newborns delivered via LSCS delivery.

Most of the newborns were presented with the complaints of fever (46.8\%) followed by refusal of feed (39.7\%) and respiratory distress. This contrasts Shrestha P et al, where refusal of feed (42.74\%) was the commonest problem followed by fever (41.7\%). ${ }^{2}$ L. Ronfani et al observed most newborn coming with difficult breathing (32\%) followed by diarrhoea (26\%), fever, cough and vomiting (19\%) and jaundice (16\%). ${ }^{6}$

Blood culture from $13.2 \%$ newborns showed growth of pathologic organism in contrast to $54.64 \%$ observed by Shaw CK et al. ${ }^{1}$ But the value is nearly comparable with the $22 \%$ observed by Budhathoki S. ${ }^{4}$ However, 55.2\% positive cultures were obtained by AK Ako-Nai et $\mathrm{al}^{7}$ and $76 \%$ by Anil Kumar Pawa et al. ${ }^{8}$ Prior empirical therapies, referral of cases from outside with prior antibiotic therapy are likely causes for the low culture positivity rate in our institute. Our study shows 66.7\% Gram-positive culture (Staphylococcus 53.3\% and Enterococcus $13.4 \%$ ) and $33.3 \%$ Gram-negative culture, Enterobacter being the commonest one. The result is comparable with the Budhathoki $\mathrm{S},{ }^{4}$ where $\mathrm{S}$. aureus was the commonest pathogen followed by Klebsiella (18.32\%). Similar results were observed by Shrestha P et al. ${ }^{2}$ However, the result contrasts with Ayman Koutbuoy et $\mathrm{al}^{5}$ who found GBS as the commonest pathogen followed by E. coli and Staph. epidermidis. Anita Sharma et al ${ }^{9}$ found Klebsiella as the commonest organism followed by Staphylococcus.

Study shows most of the isolated organisms are sensitive to amikacin followed by Ciprofloxacin, Gentamycin and Vancomycin. This is in comparable with JN Mishra et al, ${ }^{10}$ where most of the organisms were sensitive to Gentamycin. Shrestha $\mathrm{P}$ et $\mathrm{al}^{2}$ also found that most of the organisms sensitive to aminoglycosides (Amikacin and Gentamycin) and third-generation cephalosporins. In our study $79.16 \%$ of Staphylococcus isolates are sensitive to amikacin, $58.33 \%$ are sensitive to ciprofloxacin and gentamycin and 54\% are sensitive to vancomycin, while $100 \%$ were resistant to penicillin. This is comparable with Shaw CK et al ${ }^{1}$ where Staphylococcus isolates were $92 \%$ sensitive to amikacin, $100 \%$ sensitive to Vancomycin and imipenem-cilastatin, while $100 \%$ were resistant to Penicillin.

Positive blood culture was found in $15.5 \%$ of cases, who had $\mathrm{h} / \mathrm{o}$ leaking and $12 \%$ of them without h/o leaking. Among the culture positive cases, $83.32 \%$ had leaking for more than 12 hours. This is greater than the value observed by Gerd Faxelius et al,3 who found $48 \%$ cases with positive blood culture with h/o prolonged rupture of membrane ( $>12 \mathrm{hrs}$.) before delivery. The study found positive culture in $17.94 \%$ preterm newborns, while culture was positive in only 
$12.58 \%$ term newborns. The result contrasts Budhathoki $\mathrm{S}^{4}$ who found $20 \%$ preterm and $25 \%$ term neonates were culture positive. Gerd Faxelius et al $^{3}$ showed $55 \%$ of the infants with early onset septicaemia (culture positive) were preterm.

Out of 325 newborns 263 (80.9\%) improved after proper treatment, while $62(19.1 \%)$ did not. Among 43 culture positive cases 39 (90.69\%) improved, while $9.30 \%$ did not. This contrasts with JN Mishra et al,10 where mortality in culture positive cases was $61.7 \%$

The limitation of this study is that, since the study was retrospective all the required information could not be found with absence of most of relevant antenatal history of mother.

\section{CONCLUSION}

Male sex has more tendencies to develop neonatal sepsis than female. The risk of developing sepsis in male child is almost twice that of female child, which was statistically significant. The various risk factors are leaking, low birth weight, size corresponding to gestational age or prematurity. Fever, not sucking well, resp. distress, jaundice, lethargy, vomiting and seizure were the main chief complaints. Blood culture positivity rate was $13.2 \%$ with predominance of grampositive organisms. Staphylococcus aureus was the most common isolated pathogen (53.2\%) followed by Enterobacter and Enterococcus. Seventy-nine percent of Staphylococcus was sensitive to Amikacin, 58.33\% sensitive to Ciprofloxacin and Gentamycin and $54 \%$ sensitive to Vancomycin.

\section{REFERENCES}

[1] Shaw CK, Shaw P, Thapalial A. Neonatal sepsis bacterial isolates and antibiotic susceptibility patterns at a NICU in a tertiary care hospital in western Nepal: Kathmandu University Medical Journal 2007;5(2):15360.
[2] Shrestha P, Das BK, Bhatta NK, et al. Clinical and bacteriological profiles in blood culture positive sepsis in newborns. J Nepal Paediatric Society 2007;27(2):64-7.

[3] Faxelius G, Bremme K, Kvist-Christensen K, et al. Neonatal septicaemia due to group B streptococci perinatal risk factors and outcome of subsequent pregnancies. J Perinat Med 1988;16(5-6):423-30.

[4] Shah GS, Budhathoki S, Das BK, et al. Risk factors in early neonatal sepsis. Kathmandu University Medical Journal 2006;4(2):187-91.

[5] Koutbuoy A, Habibullah J. Neonatal sepsis in Dubai, United Arab Emirates. Journal of Tropical Paediatrics 1995;41(3):177-80.

[6] Ronfani L, Vilarim JNA, Dragovich D, et al. Signs of severe bacterial infections in neonates. Journal of Tropical Pediatrics 1999;45:48-51.

[7] Ako-Nai K, Adejuyigbe J, Ajayi M, et al. The bacteriology of neonatal septicaemia in Ile-Ife, Nigeria. Journal of Tropical Paediatrics 1999;45(3):146-51.

[8] Pawa AK, Ramji S, Prakash K, et al. Neonatal nosocomial infection: profile and risk factors. Indian Pediatrics 1997;34(4)297-302.

[9] Sharma A, Kutty KCV, Sabharwal U, et al. Evaluation of sepsis screen for diagnosis of neonatal septicaemia. Indian Journal of Paediatrics 1993;60(4):559-63.

[10] Mishra JN, Rai MG, Chakraborty S, et al. Study of neonatal septicaemia. Indian Paediatrics 1985;22:2815. 